Estudios Constitucionales, Año 16, No 2, 2018, pp. 51-88

ISSN 07180195

Centro de Estudios Constitucionales de Chile Universidad de Talca

"El (des) control de constitucionalidad en Colombia"

David Mendieta González - Mary Luz Tobón Tobón

\title{
EL (DES) CONTROL DE CONSTITUCIONALIDAD EN COLOMBIA*
}

\author{
The Constitutional (DE) CONTROL IN Colombia
}

\author{
DAVID MENDIETA GonZÁLEZ ${ }^{* *}$ \\ Universidad de Medellín \\ dmendieta@udem.edu.co \\ MARY LuZ TOBÓN TOBÓN ${ }^{* * *}$ \\ Universidad Autónoma Latinoamericana \\ mary.tobon@unaula.edu.co
}

RESUMEN: El control de constitucionalidad, entendido como el conjunto de mecanismos y procedimientos encaminados a hacer efectiva la Constitución, es un asunto problemático en Colombia, pero, al mismo tiempo, apasionante. Influenciados por otros modelos constitucionales y aportando elementos propios, hemos construido un complejo sistema de control de constitucionalidad. Establecer quiénes son los llamados a hacer efectiva la Constitución y determinar si tener tantos garantes en el control constitucional colombiano, configura una ventaja o una desventaja, son los propósitos de la presente investigación. La metodología utilizada es la descriptiva analítica, con la cual se pudo demostrar que permitirles a muchas autoridades velar por la Constitución puede generar inseguridad, complejidad y conflictos de competencia.

ABSTRACT: The control of constitutionality, understood as the set of mechanisms and procedures aimed at making the Constitution effective, is a problematic issue in Colombia, but at the same time exciting. Influenced by other constitutional models, contributing their own elements, we have built a complex constitutional control system. Establishing who are called to make the Constitution effective and determine if having so many guarantors in the Colombian constitutional control, constitutes an

\footnotetext{
* Trabajo recibido el 26 de noviembre de 2016 y aprobado el 10 de octubre de 2018. El presente trabajo hace parte de un proyecto de investigación realizado de manera conjunta por los dos docentes de la Facultades de Derecho de la Universidad de Medellín y de la Universidad Autónoma Latinoamericana.

** Abogado, Especialista en Derecho Constitucional y Magíster en Derecho de la Universidad de Antioquia. Diploma de Estudios Avanzados (DEA) y Doctor en Derecho Constitucional de la Universidad Complutense de Madrid. Profesor de tiempo completo de la Universidad de Medellín, miembro del Grupo de Investigaciones Jurídicas de la Facultad de Derecho de la Universidad de Medellín.

*** Abogada de la Universidad de Antioquia, Especialista en Derecho Administrativo de la Universidad de Medellín. Diploma de Estudios Avanzados (DEA) y Doctora en Derecho Constitucional de la Universidad Complutense de Madrid. Investigadora de tiempo completo de la Universidad Autónoma Latinoamericana de Medellín.
} 
advantage or a disadvantage, are the purposes of the present investigation. The methodology used is the analytical descriptive. Which allowed to demonstrate that allowing many authorities to watch over the Constitution can generate insecurity, complexity and conflicts of competence.

PALABRAS CLAVE: Constitución, supremacía constitucional, control de constitucionalidad, Corte Constitucional.

KEY WORDS: Constitution, constitutional supremacy, constitutionality control, constitutional court.

\section{INTRODUCCIÓN}

Este artículo aborda el tema del control de constitucionalidad en Colombia, haciendo énfasis en qué normas integran la Constitución, quiénes están facultados para velar por su cumplimento y mediante cuáles procedimientos. Al evidenciar las muchas normas que tienen rango constitucional, los conflictos surgidos entre los garantes de la Constitución y las falencias de algunos mecanismos, se pretende demostrar que el sistema colombiano para hacer efectiva la Constitución es complejo, inseguro y eludible.

La supremacía constitucional en Colombia no es determinada solo por el texto superior de 1991, sino que es un conjunto normativo amplio e inacabado que se ha denominado Bloque de Constitucionalidad. Según el artículo 241 de nuestra Constitución, a la Corte Constitucional se le confía la guarda y cuidado de la supremacía e integridad de la Carta Política. Lo que llevaría a pensar que en Colombia existe un modelo de control concentrado, al estilo italiano, alemán o español, pero no es así pues existen otras autoridades facultadas (conforme a los artículos constitucionales 4, 93, 94, 237 numeral 2, entre otros), para realizar control de constitucionalidad.

Así, son competentes para efectuar control concreto los jueces, cuando deciden tutelas; los servidores públicos y los particulares cuando al tener el deber de aplicar una norma jurídica, la inaplican, haciendo uso de la excepción de inconstitucionalidad por la norma ser contraria a la Constitución en el caso concreto. Se configura así un tipo de control que la Corte Constitucional ha llamado difuso funcional, en los siguientes términos:

"Como bien es sabido, el control de constitucionalidad en Colombia se vio reforzado con la creación de la Corte Constitucional. Sin embargo, no por ello puede afirmarse que nuestro pais ha adoptado el llamado 'control concentrado' o austríaco, pues en realidad este sigue siendo de carácter difuso funcional'.

1 Corte Constitucional de Colombia, Sentencia C 037 de 1996. M.P. Vladimiro Naranjo Mesa. 
Pero no debe confundirse con el modelo norteamericano en el que solo los jueces son los llamados a velar por el cumplimiento de la Carta. Las muchas autoridades que lo realizan y los múltiples mecanismos existentes han generado en Colombia un complejo sistema de salvaguarda constitucional.

Del control abstracto en nuestro país se encargan la Corte Constitucional, el Consejo de Estado y la jurisdicción contencioso administrativa, pero también existen controles previos y posteriores; formales y materiales; por vía de acción y automáticos. Recientemente ha surgido una nueva tipología de normas en Colombia que buscan implementar el acuerdo de paz celebrado entre el Estado y la guerrilla de las FARC-EP. Aprobadas por un trámite rápido que ha sido llamado fast track y que tienen un control de constitucionalidad especial.

Frente a quiénes son los llamados a hacer cumplir la Constitución; tenemos elementos propios del control de constitucionalidad concentrado, como la existencia de un Tribunal Constitucional, pero nuestro modelo faculta a muchos otros a ser garantes de la Constitución, lo que va más allá de los modelos difusos. Este sistema de garantías constitucionales ha tenido críticos dentro de la doctrina colombiana:

"Para llegar a mi conclusión final en este acápite, considero pertinente tener en cuenta una visión realista de la situación de nuestro sistema de control de constitucionalidad imperante; su realidad nos muestra un sistema desarticulado, mixto y complejo, donde constitucionalmente se habilita a la Corte Constitucional para ejercer funciones relativas a la guarda de la integridad de la Carta politica, entendiéndose según el tenor literal de la ley que nuestro sistema es de carácter concentrado; sin embargo a su vez se contempla en nuestras instituciones el ejercicio del control difuso de constitucionalidad, debido a que según un criterio amplio del articulo 4 de la Carta, existe un deber genérico para que todos los llamados a ejercer jurisdicción, hagan primar la Constitución sobre la ley"2.

También hay autores que defienden el modelo de control de constitucionalidad existente, tal es el caso de Gaona $\mathrm{Cruz}^{3}$ quien afirma:

"El sistema de control constitucional más eficiente, completo, experimentado, avanzado y depurado de Occidente y por lo tanto del orbe, pues aglutina la organización, los mecanismos y la operancia de todos los existentes".

2 Bernal Cano (2002), p. 294.

3 Gaona Cruz (1984), p. 67. 
A finales del siglo XVIII, Sieyès se hacía las siguientes preguntas: "Una Constitución o es un cuerpo de leyes obligatorias o no es nada. Ahora bien, si es un código de leyes obligatorias resulta preciso preguntarse dónde residirá el guardián, la magistratura de ese código... todas las leyes sea cual fuere su naturaleza, suponen la posibilidad de infracción y, consiguientemente, la necesidad imperiosa de hacerlas obedecer" ". Tratando de responder las preguntas hechas por Sieyès, a continuación se establecerá a qué puede llamarse Constitución en Colombia (1), quiénes son los competentes para hacerla cumplir y mediante qué procedimientos (2) y al final se propondrán algunas conclusiones acerca de las ventajas o desventajas de tener un sistema con tantos garantes constitucionales.

\section{La Supremacía Constitucional en Colombia}

La supremacía constitucional se encuentra expresamente reconocida por el texto superior en el artículo $4^{\circ}$ al declarar que la Constitución es norma de normas, y en todo caso de incompatibilidad entre esta y la ley u otra norma, debe prevalecer la Constitución. Es en el orden jurídico vigente, el máximo referente al cual deben someterse las leyes, actos administrativos, decisiones judiciales y todas actuaciones de los órganos del poder público que, precisamente, la Constitución ha establecido5.

Recién expedida la Carta Política de 1991, que señalaba que los tratados internacionales sobre derechos humanos ratificados por Colombia, y que consagran derechos que no pueden ser suspendidos bajo estados de excepción prevalecen en el orden jurídico interno ${ }^{6}$, surgió la discusión acerca de qué tenía mayor nivel jerárquico: ¿el texto de la Constitución o los tratados a los que se refería el artículo 93? La Corte Constitucional solucionó el problema trayendo del constitucionalismo francés la noción de Bloque de Constitucionalidad ${ }^{7}$.

Por lo anterior, en Colombia el articulado de la Constitución de 1991 no es el único referente de validez del ordenamiento jurídico, pues hay otras normas de rango constitucional, diferentes a las consagradas en el texto superior y que están al mismo nivel de este y juntas forman el denominado Bloque de

\footnotetext{
4 Sieyes (1791).

5 Corte Constitucional de Colombia, Sentencia C 400 de 2013. M.P. Nilson Pinilla.

6 Artículo 93, Constitución Política de Colombia de 1991.

7 Rubio Llorente (1989), pp. 9-37.
} 
Constitucionalidad ${ }^{8}$, el cual está integrado por aquellas reglas y principios del orden constitucional a las cuales deben sujetarse las normas de rango inferior que conforman el orden jurídico nacional. Al texto constitucional se incorporaron mandatos de rango supraestatal encaminados a hacer efectivos los derechos humanos. Esa incorporación la autorizó el constituyente de 1991 a través de los artículos 9, 44, 53, 93, 94, 101, 214 y 241 de la Constitución Política de Colombia. Por lo tanto, no solo la Constitución escrita, sino todas las normas que conforman el Bloque de Constitucionalidad, son normas de normas y, por ende, referentes de validez 9 .

La Corte Constitucional colombiana ha expresado que existe el Bloque de Constitucionalidad entendido de dos maneras: el Bloque de Constitucionalidad en sentido estricto y el Bloque de Constitucionalidad en sentido amplio:

"Resulta posible distinguir dos sentidos del concepto de Bloque de Constitucionalidad. En un primer sentido de la noción, que podría denominarse Bloque de Constitucionalidad stricto sensu se ha considerado que se encuentra conformado por aquellos principios y normas de valor constitucional, los que se reducen al texto de la Constitución propiamente dicha y a los tratados internacionales que consagren derechos humanos cuya limitación se encuentre prohibida durante los estados de excepción (C.P., artículo 93). Más recientemente, la Corte ha adoptado una noción lato sensu del Bloque de Constitucionalidad según la cual aquel estaría compuesto por todas aquellas normas, de diversa jerarquía, que sirven como parámetro para llevar a cabo el control de constitucionalidad de la legislación" 10 .

Las normas del Bloque de Constitucionalidad se han de interpretar en forma consistente con el texto de la Carta Política, de manera que se integren con este en forma armónica, para constituir un parámetro coherente de obligatorio cumplimiento para el legislador y demás poderes públicos. Además, la pertenencia de una determinada norma internacional al Bloque de Constitucionalidad no

8 Uno de los primeros asuntos en los que la Corte Constitucional de Colombia desarrolló la doctrina del Bloque de Constitucionalidad fue en lo concerniente a la obediencia debida de los militares. Lo anterior en sentencias tales como la C 225 de 1995 y la C 578 de 1995, en las que el Tribunal Constitucional colombiano decide tomando como parámetros de constitucionalidad, los cuatro convenios de Ginebra y sus protocolos adicionales. Durante la vigencia de la Constitución Nacional de 1886, y los primeros años de la Constitución Política de 1991, no se consideraban parte de la Constitución ni referente de validez normativa a los tratados internacionales sobre derechos humanos.

9 Mendieta (2016), p. 72.

10 Corte Constitucional de Colombia, Sentencia C 191 de 1998. M.P. Eduardo Cifuentes Muñoz. 
puede ser interpretada en términos de que siempre prevalezca sobre la Constitución Política, sino que dicha inclusión conduzca necesariamente a adelantar interpretaciones armónicas y sistemáticas entre disposiciones jurídicas de origen nacional e internacional, pero de rango constitucional ${ }^{11}$.

Desde el año 2006, en pro de hacer cumplir el Pacto de San José, la Corte Interamericana de Derechos Humanos ha hablado en términos de control de convencionalidad y les ha ordenado a los Estados que suscribieron y ratificaron este tratado internacional, que a la hora de hacerlo cumplir, no solo tengan en cuenta la Convención Americana, sino también la interpretación que de esta ha hecho la Corte Interamericana:

"Cuando un Estado ha ratificado un tratado internacional como la Convención Americana, sus jueces, como parte del aparato del Estado, también están sometidos a ella, lo que les obliga a velar por que los efectos de las disposiciones de la Convención no se vean mermadas por la aplicación de leyes contrarias a su objeto y fin, y que desde un inicio carecen de efectos jurídicos. En otras palabras, el Poder Judicial debe ejercer una especie de 'control de convencionalidad' entre las normas jurídicas internas que aplican en los casos concretos y la Convención Americana sobre Derechos Humanos. En esta tarea, el Poder Judicial debe tener en cuenta, no solamente el tratado, sino también la interpretación que del mismo ha hecho la Corte Interamericana, intérprete última de la Convención Americana"12.

Por lo anterior, es preciso aclarar que en este artículo, cuando aludimos al control de constitucionalidad, no desconocemos la existencia e importancia del control de convencionalidad porque, tal y como se dijo, nuestra concepción de Constitución no se reduce al articulado del texto de 1991, sino que es un conjunto normativo mucho más amplio que incluye la Convención Americana de Derechos Humanos y demás tratados internacionales sobre esta materia y que hacen parte del bloque de constitucionalidad. Mucho antes de que la Corte Interamericana de Derechos Humanos hablase de control de convencionalidad ${ }^{13}$, quienes en nuestro país están facultados para velar por el cumplimiento de la Constitución, al hacerlo, también velaban por el Pacto de San José. Aunque en

11 Corte Constitucional de Colombia, Sentencia C 028 de 2006. M.P. Humberto Sierra Porto.

12 Almonacid Arellano y otros vs. Chile (2006). Corte Interamericana de Derechos Humanos, 26 de septiembre de 2006, párrafo 124.

13 "El concepto de control de convencionalidad fue establecido formalmente por la CIDH, por primera vez, en forma unánime, en la sentencia Almonacid Arellano y otros vs. Chile, el 26 de septiembre de 2006 ...”. Nogueira (2017), p. 11. 
la doctrina internacional haya autores que establezcan la necesidad de diferenciar el control de constitucionalidad del control de convencionalidad ${ }^{14}$, en Colombia ambos controles no pueden entenderse de manera independiente.

En nuestro caso, el control de constitucionalidad se hace aún más complejo pues, según el Acto Legislativo 02 de 2017, los contenidos del acuerdo de paz celebrado entre el Estado colombiano y la guerrilla de las FARC-EP, que tengan relación con derechos fundamentales y derecho internacional humanitario, son referente de validez, interpretación y desarrollo de las leyes y demás normas jurídicas que busquen implementar lo pactado. En favor de blindar el acuerdo, se estableció que esta cláusula estaría vigente durante los tres siguientes períodos presidenciales, es decir, hasta el 7 de agosto del año 203015. Es importante resaltar que la anterior reforma constitucional aprobada por trámite especial, obliga a todas las autoridades del Estado colombiano a cumplir con lo pactado en los siguientes términos:

"Las instituciones y autoridades del Estado tienen la obligación de cumplir de buena fe con lo establecido en el Acuerdo Final. En consecuencia, las actuaciones de todos los órganos y autoridades del Estado, los desarrollos normativos del Acuerdo Final y su interpretación y aplicación deberán guardar coherencia e integralidad con lo acordado, preservando los contenidos, los compromisos, el espiritu y los principios del Acuerdo Final".

En Colombia, entonces, la Constitución debe ser entendida como un amplio conjunto normativo al que se ha llamado Bloque de Constitucionalidad y, aunque no se dijo de manera expresa, al establecer que el acuerdo de paz celebrado entre el Estado colombiano y la guerrilla de las FARC-EP, en lo relacionado con derechos fundamentales y derecho internacional humanitario, es referente de validez para las leyes y demás normas que buscan implementarlo, se le dio rango constitucional al acuerdo. Esto hará que nuestro sistema sea mucho más complejo que el de la mayoría de los Estados, pues quienes velan por la Constitución colombiana deberán también ser garantes de un acuerdo de paz que se destaca por su extensión (310 páginas) y el detalle de los puntos acordados.

\footnotetext{
14 Aguilar (2017), p. 54.

15 Artículos 1 y 2 del Acto Legislativo 02 de 2017, declarado exequible por la Corte Constitucional de Colombia mediante la Sentencia C 630 de 2017, M.P. Luis Guillermo Guerrero Pérez y Antonio José Lizarazo Ocampo.
} 


\section{El (Des) control de Constitucionalidad en Colombia}

El tema del control de constitucionalidad en Colombia es problemático porque, como se hizo alusión en la primera parte del presente trabajo, quienes velan por el cumplimiento de la Constitución tienen como referentes de validez para ejercer dicha competencia un amplio conjunto normativo del que hacen parte: el articulado de la Constitución de 1991, su preámbulo, los tratados internacionales sobre derechos humanos ratificados por Colombia, los tratados limítrofes con otros Estados y gran parte del acuerdo de paz celebrado entre el Estado Colombiano y la guerrilla de las FARC-EP. Pero, además, existen muchas autoridades, mecanismos y procedimientos encaminados a hacer efectiva la Constitución. Algunos llaman a nuestro control mixto ${ }^{16}$, la Corte Constitucional realiza control de constitucionalidad sobre los actos reformatorios de la Carta ${ }^{17}$, las leyes ${ }^{18}$, los decretos con fuerza material de ley y demás normas contenidas en el artículo 241 del texto superior.

También realiza control de constitucionalidad abstracto el Consejo de Estado, que según el artículo 237, numeral $2^{19}$, conoce de las acciones de nulidad por inconstitucionalidad de los decretos del Gobierno Nacional que no sean competencia de la Corte Constitucional ${ }^{20}$. La Jurisdicción Contencioso Administrativa es competente para realizar control de constitucionalidad de los actos administrativos tales como ordenanzas, decretos de los gobernadores, acuerdos, decretos de los alcaldes y resoluciones de autoridades de menor nivel jerárquico ${ }^{21}$.

Además, realiza control de constitucionalidad concreto el poder judicial en materia de tutela conforme al artículo 86 y todos los servidores públicos y los particulares con el deber de aplicar una norma, pues están facultados para

\footnotetext{
16 Por ejemplo, Brewer-Carías (1995).

17 Los actos reformatorios de la Constitución solo pueden ser cuestionables por vicios formales y hay un año para demandarlos, lo anterior conforme a lo establecido en los artículos 379 y 241-2 de la Constitución Política de Colombia.

18 Las leyes son cuestionables por vicios formales y materiales, en el primer caso durante el año contado desde la publicación de la norma, en el segundo, en cualquier tiempo. Artículo 241 de la Constitución Política de Colombia.

19 También son sustento normativo de la acción de nulidad por inconstitucionalidad ante el Consejo de Estado los artículos 37 numeral 9 y 49 de la Ley No 270 de 1996 y 135 de la Ley No 1437.

20 Corte Constitucional de Colombia, Sentencia C 415 de 2012. M.P. Mauricio González Cuervo.

21 Lo anterior mediante el medio de control denominado nulidad y que es regulado por el artículo 137 de la Ley No 1437.
} 
inaplicarla por la excepción de inconstitucionalidad, acorde a lo establecido en el artículo 4, en ambos casos del texto constitucional.

El sistema colombiano de garantías para hacer efectiva la Constitución, ha sido calificado como el más antitécnico de los existentes en Occidente por Carlos Restrepo Piedrahita, importante estudioso de la historia del derecho constitucional en el país, quien lo expresó en los siguientes términos:

"El abigarrado sistema colombiano de control de constitucionalidad es el más antitécnico de los que contemporáneamente existen en los Estados. Es la más hipertrófica y sofisticada forma del denominado control difuso. Nótese que el carácter difuso del método americano se limita apenas al ámbito judicial. En Colombia por interpretación extensiva y ultraextensiva comprende al legislativo, al ejecutivo y al judicial. $Y$ más todavia: adicionados al régimen incidental o de excepción -dentro de cual aún sin petición de parte pueden ponerlo en práctica las distintas autoridades- se hallan los otros medios de control especifico o regulado que atrás fueron enumerados. El enunciado tradicional todavía explícito en la letra del artículo 214 (originado en el artículo 41 de la reforma de 1910) de que la Corte Suprema de Justicia tiene atribuida la guarda de la integridad de la Constitución, no es ya exclusiva de ese organismo jurisdiccional. También lo es del Consejo de Estado desde 1945. También del Presidente de la República. Lo son los gobernadores. Los Tribunales administrativos. Y cualesquiera otras autoridades que tengan la función de aplicar las leyes. Peor que sistema de control difuso, trátase de control anárquico"22.

A continuación, se hará una descripción y un análisis de las múltiples autoridades existentes en Colombia que realizan control de constitucionalidad y algunas de sus particularidades, y se intentará demostrar las falencias de un sistema de control de constitucionalidad con tantos garantes.

\subsection{Control de constitucionalidad realizado por la Corte Constitucional}

Cumpliendo con el deber de velar por la supremacía e integridad de la Constitución, la Corte Constitucional colombiana realiza cuatro tipos de control de constitucionalidad. El primero es el control abstracto sobre normas, el segundo es la eventual revisión de constitucionalidad de las tutelas presentadas en el país, el tercero es el control concreto de constitucionalidad cuando ordena la inaplicación de normas utilizando la excepción de inconstitucionalidad y, el

22 Restrepo (1978), pp. 92, 95 y 96. 
cuarto, es el control de constitucionalidad a los mecanismos de participación ciudadana en los términos previstos en la Constitución y en las leyes estatutarias que regulan la materia ${ }^{23}$.

Ejerciendo dichos controles, el Tribunal Constitucional colombiano expide tres tipos de sentencias que a continuación se explicarán.

Sentencias $\mathrm{C}$ que son decisiones acerca de la constitucionalidad de normas. La Corte colombiana no está facultada para determinar la constitucionalidad de cualquier norma jurídica, su competencia se encuentra establecida en los artículos 241 y $10^{\circ}$ transitorio del texto constitucional y corresponde a actos reformativos de la Constitución, que en Colombia son: el acto legislativo ${ }^{24}$ que tiene control de constitucionalidad posterior, por vía de acción, solo por razones procedimentales y hay un año para demandarlo desde su promulgación; el referendo y la asamblea constituyente tienen un doble control. Por un lado, el que recae sobre la ley de convocatoria que es automático y previo al pronunciamiento $\operatorname{popular}^{25} \mathrm{y}$, por el otro, el control que recae sobre el acto de reforma que es por vía de acción ciudadana, la cual solo puede instaurarse dentro del año posterior a su promulgación y por razones procedimentales ${ }^{26}$; las leyes, por regla general, tienen control de constitucionalidad posterior a su promulgación y por vía de acción ciudadana. Por razones formales hay un año para demandarlas y, por razones materiales, en cualquier tiempo, excepcionalmente algunas leyes tienen control de constitucionalidad automático ${ }^{27}$.

Para concluir, los decretos del Gobierno Nacional que se encuentran en el citado artículo 241 y que son: decretos legislativos o de estados de excepción ${ }^{28}$ -que tienen control automático y posterior a su entrada en vigencia ${ }^{29}$-; los

23 Corte Constitucional de Colombia, Sentencia T 203 de 2002. M.P. Manuel José Cepeda.

24 Artículos 374, 375 y 241 No 1 de la Constitución Política de Colombia.

25 Artículos 376, 378 y 241 No 2 de la Constitución Política de Colombia.

26 Artículo 379 de la Constitución Política de Colombia.

27 Son ejemplo de leyes que tienen control de constitucionalidad automático: los proyectos de leyes estatutarias (arts. 152, 153 y 241 No $8^{\circ}$ de la Constitución Política), proyectos de ley objetados por inconstitucionales por el Gobierno Nacional e insistidos por el Congreso de la República (arts. 167 y 241 No $8^{\circ}$ de la Constitución Política), las leyes de convocatoria a referendo y Asamblea Constituyente (artículos 376, 378 y 241 No $2^{\circ}$ de la Constitución Política) y las leyes que ratifican tratados internacionales (artículo 241 No $^{\circ} 10^{\circ}$ Constitución Política).

28 Artículos 212, 213, 214, 215 y 241 No 7 de la Constitución Política de Colombia.

29 Tóón y Mendieta (2017), p. 67. 
decretos ley o de facultades extraordinarias dadas por el Congreso al Gobierno Nacional ${ }^{30}$; el decreto Plan Nacional de Inversiones ${ }^{31}$-ambos tienen control de constitucionalidad posterior y por vía de acción ciudadana-32. Los decretos de los que habla el artículo transitorio $10^{\circ}$ son aquellos que expidió el Gobierno Nacional en uso de facultades extraordinarias, dadas por el constituyente de 1991 en los primeros 9 artículos transitorios. También conoce la Corte de la constitucionalidad de los tratados internaciones ${ }^{33}$, de los referendos sobre leyes, de los plebiscitos y de las consultas populares del orden nacional ${ }^{34}$.

Para el caso de los decretos, inicialmente la Corte Constitucional estableció como criterio para determinar su competencia que el decreto fuese uno de los que se encuentran enunciados en los artículos 241 y $10^{\circ}$ transitorio de la Carta. Sin embargo, esta Alta Corte se ha declarado competente para conocer de las acciones de inconstitucionalidad instauradas contra decretos expedidos por el Gobierno Nacional amparado por facultades dadas por artículos transitorios de la Constitución, diferentes a los que se refiere el artículo $10^{\circ}$ transitorio ${ }^{35}$; decretos del Gobierno Nacional con fuerza de ley estatutaria expedidos por facultades supletorias y transitorias dadas por actos legislativos - categoría que aunque no existe en la Constitución, ha sido objeto de control por parte de nuestra Corte 36 -; y otros decretos que no aparecen enunciados en los citados artículos constitucionales 241 y $10^{\circ}$ transitorio y que, en su conjunto, la Corte Constitucional colombiana ha llamado decretos y normas de autoridad cuya

30 Artículo 150 No 10 de la Constitución Política de Colombia.

31 Artículo 341 de la Constitución Política de Colombia.

32 Artículo 241 No $5^{\circ}$ de la Constitución Política de Colombia.

33 Artículo 241 No 10 de la Constitución Política de Colombia.

34 Artículo 241 No 3 de la Constitución Política de Colombia.

35 "En diferentes ocasiones esta Corporación ha establecido su competencia para conocer sobre las demandas de constitucionalidad instauradas contra el Decreto 2067 de 1991”. Corte Constitucional de Colombia, Sentencia C 534 de 2000. M.P. Eduardo Cifuentes Muñoz.

36 Es el caso del Acto Legislativo 03 de 2002, en su artículo transitorio le entregó facultades al Gobierno Nacional para expedir, modificar y adicionar leyes estatutarias como la 270 de 1996 o de la administración de justicia y la Ley No 1095 de 2006 o ley del habeas corpus, con lo que la Corte claramente creó una nueva categoría de decretos, "los decretos estatutarios", a pesar de que nuestra Constitución expresamente prohíbe en el artículo 153 que el Congreso de la Republica le otorgue facultades extraordinarias al Gobierno Nacional para expedir este tipo de normas, sin embargo la competencia no se la entregó al Gobierno una ley sino un acto legislativo que en Colombia es un acto reformativo de la Constitución. 
competencia es especial o atípica ${ }^{37}$. Lo anterior es un claro ejemplo de competencia autoatribuida que es muy peligrosa para el Estado de derecho.

Para concluir las normas conocidas por la Corte Constitucional, en el año 2016 en Colombia posibilitó una nueva tipología y constituidas por aquellas aprobadas mediante un trámite abreviado y que han sido llamadas normas de fast track.

El Congreso de la República, mediante una reforma constitucional ${ }^{38}$, se facultó a sí mismo y al Presidente de la República para expedir actos legislativos y leyes y, en el caso del Presidente, decretos con fuerza de ley durante un período de seis meses prorrogables por otros seis meses (la prórroga finalizó el 30 de noviembre de 2017). Todo ello en procura de implementar el acuerdo de paz celebrado entre el Estado colombiano y la guerrilla de las FARC-EP. Estas normas tienen un control de constitucionalidad a cargo de la Corte, posterior, automático y único ${ }^{39}$ y para este tipo de normas se creó un trámite de revisión de constitucionalidad especial ${ }^{40}$.

El control abstracto de constitucionalidad que realiza la Corte Constitucional colombiana puede ser por vía de acción ciudadana -que es una de las instituciones más relevantes del constitucionalismo colombiano ${ }^{41}-\mathrm{o}$ automático.

37 Corte Constitucional de Colombia, Sentencia C 049 de 2012. M.P. Mauricio González Cuervo.

38 Acto legislativo 01 de 2016, declarado constitucional mediante la Sentencia C 699 de 2016. M.P. María Victoria Calle Correa.

39 "Los proyectos de ley y de acto legislativo tramitados mediante el Procedimiento Legislativo Especial para la Paz tendrán control automático y único de constitucionalidad, posterior a su entrada en vigencia. Las Leyes Estatutarias tendrán control previo, de conformidad con lo previsto en el artículo 153 de la Constitución. El control de constitucionalidad de los actos legislativos se hará solo por vicios de procedimiento en su formación. Los términos de esta revisión para leyes y actos legislativos se reducirán a la tercera parte de los del procedimiento ordinario y no podrán ser prorrogados”. Artículo $1^{\circ}$ literal K) del acto legislativo 01 de 2016.

"Los decretos con fuerza de ley que se dicten en desarrollo de este artículo tendrán control de constitucionalidad automático posterior a su entrada en vigencia. El procedimiento de revisión de constitucionalidad de estas disposiciones deberá surtirse por parte de la Corte Constitucional dentro de los dos meses siguientes a su expedición”. Artículo 2ºl decto legislativo 01 de 2016.

40 El control de constitucionalidad que realiza la Corte Constitucional se encuentra reglado en el Decreto 2067 de 1991 y el acuerdo de 02 de 2015 de la Corte Constitucional, allí se encuentran los términos para que la Corte decida sobre la constitucionalidad de las diferentes normas, ya sea por vía de acción o control automático, sin embargo para normas fast track se redujeron los términos y se expidió un decreto especial para regular su control de constitucionalidad, dicho decreto es el 121 de 2017, declarado constitucional mediante la Sentencia C 174 de 2017. M.P. María Victoria Calle Correa.

41 En 1910 hubo en Colombia una gran reforma constitucional que facultó al ciudadano a acudir a la Corte Suprema de Justicia para cuestionar leyes por ser inconstitucionales, eso significa que nuestra Corte Suprema estaba haciendo control abstracto de constitucionalidad y por vía de acción 10 años antes que 
Las sentencias C tienen efectos erga omnes. Si la Corte decide pronunciarse de fondo, lo hace en términos de exequibilidad (constitucional) o inexequibilidad (inconstitucional), pero también es posible que no lo haga y en ese caso la sentencia es llamada inhibitoria y, según la misma Corte, tiene carácter excepcional ${ }^{42}$. Los fallos inhibitorios no son propios del control de constitucionalidad oficioso, pues desde 1992 y hasta el año 2017, solo hubo $13^{43}$ de un total de 6.273 , lo que representa $0.2 \%$ de la totalidad de sentencias de control abstracto de constitucionalidad proferidas. En cambio, son muy comunes en las sentencias que se pronuncian frente a acciones de inconstitucionalidad presentadas por los ciudadanos, pues durante el mismo período de tiempo hubo 1.140 fallos inhibitorios, lo que representa un $18.17 \%$ de la totalidad de sentencias expedidas por el Alto Tribunal en control abstracto de constitucionalidad, lo que contradice la excepcionalidad planteada por la Corte.

Con el propósito de evitar las sentencias inhibitorias, el Tribunal Constitucional colombiano expidió la Sentencia C 1052 de 2001, donde establece que los argumentos del demandante deberán ser ciertos, claros, suficientes, pertinentes y específicos, y cada uno de estos términos representa un deber del accionante. El cumplimiento de lo anterior es revisado en dos momentos: primero, por el magistrado sustanciador antes de la admisión de la demanda y, segundo, cuando se reúne la Corte en pleno para fallarla. En caso de que los argumentos del accionante no cumplan con lo pedido, el magistrado sustanciador procederá a inadmitir y rechazar la demanda. Lo anterior vuelve a ser revisado cuando la Corte se reúne en pleno y, si para la mayoría de sus integrantes no se cumple, entonces la Corte deberá inhibirse y no decidir de fondo ${ }^{44}$. Lo anterior nos llevaría a pensar que, desde el año 2001, las sentencias inhibitorias desapare-

el Tribunal Constitucional austriaco y 19 años antes de que Kelsen propusiese su teoría del legislador negativo. Para un estudio más detallado de la acción de inconstitucionalidad en Colombia puede leerse Mendieta (2010).

42 Corte Constitucional de Colombia, Sentencia C 666 de 1996. M.P. José Gregorio Hernández Galindo.

43 Las sentencias C de control de constitucionalidad automático e inhibitorias expedidas por la Corte Constitucional entre 1992 y 2014 fueron: C 457 de 1993, C 255 de 1996, C 325 de 1997, C 327 de 1997, C 036 de 1998, C 1146 de 2003, C 196 de 2009, C 321de 2009, C 323 de 2009, C 850 de 2009, C 239 de 2010, C 258 de 2014 y C 388 de 2014.

44 Corte Constitucional de Colombia, Sentencia C 1300 de 2005. M.P. Marco Gerardo Monroy Cabra. 
cerían o serían muy pocas, pero esto no sucedió e incluso en la mayoría de los años han aumentado.

A continuación se establece el porcentaje de sentencias inhibitorias en relación con las acciones de inconstitucionalidad presentadas por los ciudadanos desde el año 1992 (año en el que comenzó a funcionar la Corte) hasta el 2017 (último año del que se tienen los datos completos): 1992 (5.3\%), 1993 (6.9\%), 1994 (12.6\%), 1995 (9.2\%), 1996 (11.6\%), 1997 (9.2\%), 1998 (13.7\%), 1999 (15.4\%), 2000 (18.7\%), 2001 (22.1\%), 2002 (23.7\%), 2003 (17.7\%), 2004 (22.8\%), 2005 (27.9\%), 2006 (30.8\%), 2007 (30.8\%), 2008 (38.8\%), 2009 (22.6\%), 2010 (21.5\%), 2011 (31.5\%), 2012 (20.9\%), 2013 (28.3\%), 2014 (25.6\%), 2015 (27.9\%), $2016(22.8 \%)$ y 2017 (35.8\%).

En el mismo período de tiempo, el número de sentencias expedidas a petición ciudadana disminuyó notablemente, lo anterior porque el Tribunal Constitucional colombiano es más exigente en su proceso de admisión, siendo la principal razón de inadmisión y rechazo no cumplir con lo establecido en la Sentencia C 1052 de 2001. Frente a cada año se encuentra el número de sentencias C resultado de acciones de inconstitucionalidad presentadas por los ciudadanos, así: 1992 (38), 1993 (145), 1994 (190), 1995 (196), 1996 (300), 1997 (251), 1998 (219), 1999 (247), 2000 (348), 2001 (321), 2002 (300), 2003 (305), 2004 (285), 2005 (244), 2006 (224), 2007 (185), 2008 (224), 2009 (159), 2010 (135), 2011 (146), 2012 (191), 2013 (173), 2014 (156), 2015 (129), 2016 (166) y 2017 (106). El mayor número de acciones de inconstitucionalidad falladas se alcanza en el año 2000 (348) y, desde entonces, es evidente su disminución hasta llegar a menos de la tercera parte en 2017 (106). Aunque es cierto que el año 2017 fue especial, pues la Corte suspendió los términos para tramitar acciones de inconstitucionalidad mediante el auto 305, los años 2015 (129) y 2016 (166), corroboran lo afirmado.

Si el porcentaje de sentencias inhibitorias de la Corte Constitucional colombiana no disminuyó a partir del año 2001, pero sí el número de sentencias resultado de acciones de inconstitucionalidad, podemos concluir que el objetivo de la Sentencia C 1052 de 2001, al establecer cargas argumentativas al accionante, no era evitar las sentencias inhibitorias sino disminuir el número de acciones tramitadas por la Corte Constitucional y así evitar su colapso. Lo anterior afecta derechos constitucionales tales como la supremacía efectiva de la Constitución, acceso a la justicia, tutela efectiva, entre otros; y el mal uso de esta competencia puede convertirse en una excusa para que la Corte se niegue a fallar de manera 
discrecional ${ }^{45}$. Lo anterior le trae inseguridad a un sistema al que -en el presente artículo- le hemos evidenciado varias falencias.

Otro tipo de sentencias de la Corte Constitucional colombiana son las T que son decisiones de tutela, pues en Colombia todas las tutelas van a la Corte Constitucional $^{46}$, pero no todas son seleccionadas por la Corte para su revisión. Estas sentencias son decisiones de salas de revisión conformadas por tres magistrados y sus efectos son inter partes, en algunos casos inter pares y excepcionalmente inter comunis ${ }^{47}$.

Las sentencias U son unificadoras de jurisprudencia. En estos casos la Corte busca definir criterios en un tema que causa polémica dentro del Tribunal Constitucional, por ejemplo, cuando la tutela es contra una Alta Corte o las demás causales establecidas en su reglamento. Pueden tener los mismos efectos que las sentencias T, son decisiones de la Corte en pleno, es decir, los nueve magistrados que la integran y que establecen los lineamientos que a futuro deben seguir las diferentes salas de revisión de tutelas en casos similares.

En Colombia, las decisiones de la Corte Constitucional tienen fuerza vinculante de diferente índole, esto según el tipo de sentencia y los efectos que la propia Corte le conceda ${ }^{48}$. El máximo tribunal de constitucionalidad colombiano ha dicho que puede modular los efectos de sus sentencias según las diferentes circunstancias, en pro de la protección de los derechos fundamentales y la supremacía de la Constitución, así:

"Generalmente, los efectos de las providencias de la Corte Constitucional son diversos en cada tipo de control constitucional. Usualmente, los efectos son erga omnes y pro-futuro cuando controla normas en abstracto; son inter partes cuando decide sobre una tutela; son inter partes cuando aplica de manera preferente la Constitución en el curso de un proceso concreto; y son erga omnes cuando controla el ejercicio de los mecanismos de participación ciudadana. Sin embargo, no siempre el efecto de las providencias de la Corte han de ser los anteriormente señalados. De conformidad con la jurisprudencia de esta Corporación, la Corte Constitucional puede modular los efectos de sus sentencias. Dentro de las múltiples alternativas disponibles, la Corte puede decidir cuál es el efecto que mejor protege los derechos constitucionales y garantiza la integridad y supremacía

45 Mendieta (2017).

46 Decreto No 2591 de 1991, artículo 33.

47 Corte Constitucional de Colombia, Sentencia T 272 de 2014. M.P. María Victoria Calle Correa.

48 Corte Constitucional de Colombia, Sentencia C 539 de 2011. M.P. Luis Ernesto Vargas Silva. 
de la Constitución. Asi lo ha hecho esta Corporación cuando ejerce un control abstracto de normas, al fijar, por ejemplo, los efectos retroactivos o diferidos de las sentencias correspondientes" ${ }^{\prime 9}$.

Modular los efectos de las sentencias, fijar a voluntad la retroactividad de una decisión de constitucionalidad, denota una gran competencia y corrobora lo inseguro que puede ser el sistema del control de constitucionalidad colombiano con un tribunal con tanto poder, pocos controles y amplios márgenes de discrecionalidad. Como se verá a continuación en materia de tutela, las cosas no son mejores.

Todas las órdenes de tutela de segunda instancia, o aquellas de primera instancia que no fueron impugnadas, se envían a la Corte Constitucional para su revisión eventual. La Corte procede de manera autónoma a seleccionar las sentencias que habrá de revisar y a regresar los restantes expedientes a los despachos de origen. Debe tenerse en cuenta que, en promedio, llegan al mes al Tribunal Constitucional aproximadamente cuarenta mil tutelas (40.000) -durante la vigencia de la Constitución de 1991 en el país se han instaurado más de seis millones de estos mecanismos de protección de derechos fundamentes (6.000.000) - y al mes son seleccionadas entre 50 y 70, que serán las que darán origen a las ya mencionadas sentencias T y SU.

Colombia viene de vivir un gran escándalo en el cual se cuestionó el proceso de escogencia de tutelas por parte de la Corte Constitucional y requirió que este Tribunal, en pro de la transparencia, modificara su propio reglamento, que hoy es el Acuerdo 02 de 2015. Se estableció un sistema reglado que señala, de manera expresa, causales de escogencia de las tutelas, y se creó, además, una unidad de análisis y seguimiento al proceso de selección.

Otro de los problemas es la procedencia de la tutela contra decisiones de tribunales de cierre. Vale la pena señalar que en Colombia existen cuatro jurisdicciones y cada una de ellas cuenta con su tribunal de cierre, así: i) Corte Suprema de Justicia, máxima autoridad de la jurisdicción ordinaria; ii) Consejo de Estado, máxima autoridad de lo contencioso administrativo; iii) Corte Constitucional, máxima autoridad de la jurisdicción constitucional y iv) el Tribunal para la paz, órgano de cierre y máxima instancia de la jurisdicción especial para la paz ${ }^{50}$.

49 Corte Constitucional de Colombia, Sentencia T 203 de 2002. M.P. Manuel José Cepeda.

50 La Jurisdicción Especial para la Paz (JEP) es parte del acuerdo de paz firmado entre el Estado colombiano y la guerrilla de las FARC-EP. Pretende investigar y juzgar graves infracciones contra los derechos 
Se han presentado múltiples enfrentamientos en este sentido, pues la Corte Constitucional, en revisión de una acción instaurada contra una sentencia de las otras dos altas cortes, les ha ordenado modificarla, causando lo que en el país ha sido llamado "choque de trenes" e incluso hubo casos, donde el otro Alto Tribunal se negó a acatar lo ordenado por la Corte Constitucional. Sobre el tema, Botero y Jaramillo, han señalado que:

"De esta manera, mientras la Sala Jurisdiccional Disciplinaria del Consejo Superior de la Judicatura ha respaldado la posición de la Corte Constitucional, el Consejo de Estado y las Salas de Casación de la Corte Suprema de Justicia han revivido su oposición a la posibilidad de entablar acciones de tutela contra sentencias. Así, luego de que la Corte Constitucional declarara que una sentencia que habia declarado la pérdida de investidura de un congresista constituía una vía de hecho, la Sala Plena del Consejo de Estado decidió, en junio de 2004, que la acción de tutela era improcedente contra providencias judiciales que pusieran fin a un proceso o actuación, para lo cual remitió a lo expresado en la Sentencia C-543 de 1992 de la Corte Constitucional'51.

La tutela contra sentencias de altas cortes ha generado muchos conflictos. La Sala Laboral de la Corte Suprema de Justicia declaró la improcedencia de esta garantía contra providencias judiciales y las salas Civil y Penal de la misma Corte dijeron que no procede contra sentencias de casación, por tratarse de órganos de cierre ${ }^{52}$. Algunas salas, incluso, llegaron al extremo de no tramitar las tutelas instauradas contra sus sentencias y, sencillamente, archivaron la acción. A petición de los tutelantes, la Corte Constitucional, de manera reiterativa, le ordenó a la Corte Suprema el envío de las tutelas para su revisión. La orden se cumplió por poco tiempo y las salas de casación decidieron no volver enviarlas

humanos y el derecho internacional humanitario, cometidos con ocasión o en relación directa o indirecta con el conflicto armado colombiano. Su implementación se hizo mediante el Acto Legislativo 01 de 2017, el cual fue declarado constitucional mediante la Sentencia C 674 de 2017. M.P. Luis Guillermo Guerrero Pérez.

51 Botero y Jaramillo (s.f.), pp. 8-9.

52 En sentencia del 4 de febrero de 2005, dictada dentro del expediente número 11001-02-03-000-200500072-00 la SAla de CASACión Civil expresó: "Puestas así las cosas es claro para esta Sala que al ser la Corte Suprema de Justicia el órgano límite de la jurisdicción ordinaria, resulta manifiesto que ninguna autoridad está facultada para alterar la condición inmutable de que están revestidas sus decisiones, luego mal pueden quedar sujetas a un nuevo examen por vía de tutela así sea este efectuado por ella misma”. En relación con la Sala de Casación Penal ver la sentencia de tutela de 19 de agosto de 2004, dentro del proceso con radicación No 17389 . 
a la Corte Constitucional, a lo que esta respondió facultando a los perjudicados para instaurar nuevas acciones ante otros jueces, así:

"Primero. Decidir que los accionantes a los que se refiere la parte motiva de esta providencia, de conformidad con lo establecido en el artículo 37 del Decreto No 2591 de 1991 tienen el derecho de acudir ante cualquier juez (unipersonal o colegiado), incluyendo una Corporación de igual jerarquía a la Corte Suprema de Justicia, para reclamar mediante la acción de tutela la protección del derecho fundamental que consideran violado con la actuación de una Sala de Casación de dicha Corte. Por secretaría oficiese a cada uno de los accionantes.

"Segundo. Para otros casos en que exista la misma situación de vulneración del derecho de acceso a la administración de justicia y la no tutela judicial efectiva de sus derechos fundamentales, por no admitir a trámite la acción de tutela contra providencia de la Corte Suprema de Justicia, con fundamento en el artículo 37 del Decreto No 2591 de 1991 los ciudadanos tienen el derecho de acudir ante cualquier juez (unipersonal o colegiado), incluyendo una Corporación de igual jerarquía a la Corte Suprema de Justicia, para reclamar mediante una acción de tutela la protección del derecho fundamental que consideran violado con la actuación de una Sala de Casación de dicha Corte"53.

El conflicto entre la Corte Constitucional y las otras dos Altas Cortes colombianas llegó incluso a instancias internacionales, pues hay casos en los que el Tribunal Constitucional le ha ordenado a la Corte Suprema de Justicia o al Consejo de Estado cambiar una de sus sentencias dentro de un trámite de tutela y estas Cortes se han negado. Entonces el tutelante ha decidido acudir al Sistema Interamericano de Derechos Humanos:

"También el conflicto ha llegado hasta el sistema interamericano de derechos humanos. En el año 2001, la Sala Plena de la Corte Constitucional dictó la Sentencia SU-1185, mediante la cual dejó sin efecto una sentencia de la Sala de Casación Laboral de la Corte Suprema de Justicia, que habia negado el reconocimiento de una pensión de jubilación, $y$ le ordenó dictar una nueva providencia. Esta última Sala respondió que mantendría su sentencia. El afectado decidió presentar el caso ante la Comisión Interamericana de Derechos Humanos, la cual admitió su petición en febrero de 2004. Una situación similar se presentó con la Sentencia T-678 de 2003, en la cual la Corte Constitucional le ordenó a la Sala de Casación Civil de la Corte Suprema de Justicia que le diera trámite a una demanda de tutela contra una providencia de la Sala de Casación Penal, para lo cual habia de seguir distintos lineamientos que fijaba el mismo Tribunal Constitucional.

53 Corte Constitucional de Colombia, Auto 04 de 2004. 
También en esta ocasión la Sala de Casación Civil se negó a cumplir con la sentencia de tutela. En vista de ello, el afectado decidió acudir a la Corte Interamericana de Derechos Humanos, la cual decidió admitir el caso en febrero de 2005"54.

Como puede observarse, las relaciones entre la Corte Constitucional y las otras Altas Cortes colombianas en materia de revisión de tutelas no han sido pacíficas. En favor de mejorar esta situación, el Tribunal colombiano ha expedido sentencias tales como la C-590 de 2005 y la SU-053 de 2015, mediante las cuales ha diferenciado las causales generales y las causales especiales de procedibilidad, a las que llamó "defectos" de la tutela contra sentencias judiciales.

\subsection{Control de constitucionalidad realizado por el Consejo de Estado}

El Consejo de Estado tiene la competencia de declarar la nulidad de los decretos del Gobierno Nacional y demás actos de carácter general que, por expresa disposición constitucional, sean expedidos por entidades u organismos distintos del Gobierno Nacional, y cuyo control de constitucionalidad no sea competencia de la Corte Constitucional, lo anterior a petición de un ciudadano.

Su sustento normativo es el artículo 237, numeral 2 de la Constitución, los artículos 37, numeral 2 y 49 de la Ley No 270 de 1996 -que es la Ley Estatutaria de la Administración de Justicia- y el artículo 135 de la Ley No 1437 de 2011, también denominada Código de Procedimiento Administrativo y de lo Contencioso Administrativo. De los decretos del Gobierno Nacional, conoce en su constitucionalidad la Corte Constitucional cuando estos tienen fuerza material de Ley, y el Consejo de Estado para los demás casos ${ }^{55}$.

El Tribunal Constitucional colombiano equipara el trámite de la acción de nulidad por inconstitucionalidad ante el Consejo de Estado, con el de acción de inconstitucionalidad ante la Corte Constitucional:

"Con todo, debe advertirse que al señalar la norma que el procedimiento de la acción de nulidad por inconstitucionalidad será el mismo que el de la acción de inexequibilidad'56.

\footnotetext{
54 Botero y Jaramillo (s.f.), p. 11.

55 Corte Constitucional de Colombia, Sentencia C 560 de 1999. M.P. Carlos Gaviria Díaz.

56 Corte Constitucional de Colombia, Sentencia C 037 de 1996. M.P. Vladimiro Naranjo Mesa.
} 
Se le entrega la legitimación activa para instaurar este tipo de acciones al ciudadano, facultad que fue confirmada por el artículo 135 de la Ley No 1437 que, expresamente, consagra el derecho ciudadano de instaurar acciones ante el Consejo de Estado contra normas que no sean competencia de la Corte Constitucional. El parágrafo de este artículo fue declarado exequible por la Corte Constitucional mediante la Sentencia C 415 de 201257, y los argumentos dados por nuestro Tribunal de Constitucionalidad son de carácter extensivo, pues se declara la exequibilidad de dicho parágrafo tomando como referente normas que desarrollan la competencia de la Corte Constitucional ${ }^{58}$. La acción de nulidad por inconstitucionalidad ha sido denominada como una derivación de la simple nulidad, sin embargo, la causal de procedencia de esta es la infracción directa de la Constitución por los decretos de carácter general expedidos por el Gobierno Nacional, y no la ley, pues para ese caso se tendría el medio de control de simple nulidad. El citado artículo 135 de la Ley No 1437 dice:

"Los ciudadanos podrán, en cualquier tiempo, solicitar por sí, o por medio de representante, que se declare la nulidad de los decretos de carácter general dictados por el Gobierno Nacional, cuya revisión no corresponda a la Corte Constitucional en los términos de los artículos 237 y 241 de la Constitución Política, por infracción directa de la Constitución.

También podrán pedir la nulidad por inconstitucionalidad de los actos de carácter general que por expresa disposición constitucional sean expedidos por entidades u organismos distintos del Gobierno Nacional.

Parágrafo. El Consejo de Estado no estará limitado para proferir su decisión a los cargos formulados en la demanda. En consecuencia, podrá fundar la declaración de nulidad por inconstitucionalidad en la violación de cualquier norma constitucional. Igualmente podrá pronunciarse en la sentencia sobre las normas que, a su juicio, conforman unidad normativa con aquellas otras demandadas que declare nulas por inconstitucionales".

En Colombia, el reparto de la competencia para conocer de la constitucionalidad de los decretos del Gobierno Nacional entre la Corte Constitucional y el Consejo de Estado ha sido problemático, pues no está del todo claro cuáles son los decretos que le corresponden a uno y otro tribunal. Con la intención de solucionar esto, el Legislador, en el artículo 49 de la Ley No 270 de 1996 o Ley Estatutaria de la Administración de Justicia, intentó establecer de manera

57 Corte Constitucional de Colombia, Sentencia C 415 de 2012. M.P. Mauricio González Cuervo.

58 Corte Constitucional de Colombia, Sentencia C 415 de 2012. M.P. Mauricio González Cuervo. 
expresa los decretos expedidos por el Gobierno Nacional cuya competencia era del Consejo de Estado, pero esta enunciación fue declarada inexequible por falta de competencia del legislador estatutario para fijar límites no establecidos en la Constitución.

También se pueden presentar problemas con la división del control de constitucionalidad de las leyes y los decretos del Gobierno Nacional. Como por ejemplo, en el caso de las leyes marco y sus decretos reglamentarios. De las primeras, conoce la Corte Constitucional (artículo 241 No $4^{\circ}$ de la C. P.) y, los segundos, son competencia del Consejo de Estado (artículo 237 No 2 C. P.). Lo anterior crea la posibilidad de que sobre una misma materia u objeto haya dos pronunciamientos distintos de dos altas cortes ${ }^{59}$.

La competencia repartida entre la Corte Constitucional y el Consejo de Estado ha permitido que surja en Colombia la elusión constitucional, que es la posibilidad que tiene una autoridad de evadir el control idóneo de constitucionalidad que debería recaer sobre una norma. Un ejemplo es cuando el Gobierno Nacional, a pesar de que un tema o materia debe ser regulado por ley, lo hace a través de decreto reglamentario para que el control de constitucionalidad no lo realice la Corte Constitucional sino el Consejo de Estado, cuyas posiciones jurídicas suelen ser conservadoras en comparación con las del Tribunal Constitucional de tradición liberal. En tal sentido se ha dicho que:

"El caso de los decretos reglamentarios es grave y paradigmático, pues alli ha desaparecido todo control real. De hecho, hoy se hace cualquier cosa con un decreto reglamentario. Se evita el control constitucional y se logra la realización de una competencia por parte del Consejo de Estado, donde el control es inexistente. Esto en atención a que la competencia para controlar los decretos reglamentarios fue asignada al Consejo de Estado (artículo 237.2 de la Constitución), aconteciendo que bajo el nombre de decreto reglamentario se expide un decreto de contenido legislativo, sin realizar control'60.

Que exista una ruta que le permita al Presidente colombiano evadir el control idóneo de constitucionalidad tiene que alarmar a toda la sociedad, pero especialmente a quienes nos preocupamos por la conservación y respeto del Estado Constitucional y Democrático de Derecho, y demuestra una vez más nuestra tesis de inseguridad del modelo de garantías constitucionales del país.

59 Restrepo (2017).

60 Quinche Ramírez (2009), p. 38. 


\subsection{Control de constitucionalidad realizado por la Jurisdicción Contencioso Administrativa}

El medio de control denominado Nulidad le permite a toda persona acudir ante la Jurisdicción Contencioso Administrativa -compuesta por el Consejo de Estado, los Tribunales Contencioso Administrativos y los Jueces Administrativosy demandar actos de la administración. Su sustento normativo es el artículo 137 de la Ley No 1437 de 2011, Código de Procedimiento Administrativo y de lo Contencioso Administrativo -actualmente vigente- y lo define en los siguientes términos:

"Toda persona podrá solicitar por sí, o por medio de representante, que se declare la nulidad de los actos administrativos de carácter general.

Procederá cuando hayan sido expedidos con infracción de las normas en que deberían fundarse, o sin competencia, o en forma irregular, o con desconocimiento del derecho de audiencia y defensa, o mediante falsa motivación, o con desviación de las atribuciones propias de quien los profirió.

También puede pedirse que se declare la nulidad de las circulares de servicio y de los actos de certificación y registro...".

En este caso, no hablamos de una "acción de inconstitucionalidad", sino de un medio de control llamado "nulidad". No solo están facultados los ciudadanos, pues el artículo 137 del Código de Procedimiento Administrativo y de lo Contencioso Administrativo faculta a "toda persona" para instaurarlo, lo que abre las posibilidades a las personas jurídicas y extranjeros, los cuales están excluidos de la acción de inconstitucionalidad y de la acción de nulidad por inconstitucionalidad. No se trata solo de garantizar la Constitución, sino también la ley, eso significa que los actos administrativos pueden ser demandados por ser inconstitucionales y/o ilegales, pues el referente de validez para ellos es la Constitución y la ley:

"La acción de nulidad tiene un sólido soporte en el principio de legalidad que surge, principalmente, del conjunto normativo contenido en los artículos 1, 2, 6, 121, 123, inciso $2^{\circ}, 124$ de la C.P., pero asi mismo tiene su raiz en las normas que a nivel constitucional han institucionalizado y regulado la jurisdicción de lo contencioso administrativo (artículos 236, 237-1-5-6 y 238)"61.

61 Corte Constitucional de Colombia, Sentencia C 513 de 1994. M.P. Antonio Barrera Carbonell. 
La nulidad procede no solo contra actos generales, sino también cuando existe un acto de carácter particular o individual ${ }^{62}$, si el interés del accionante es general y no busca un beneficio personal.

De esta manera, la pretensión de nulidad del acto administrativo demandado es la protección del orden jurídico con el propósito de que quede sin efecto, por contrariar las normas superiores del derecho como lo son la Constitución y la ley. Esta acción se encuentra consagrada en interés general para que prevalezcan la defensa de la constitucionalidad y la legalidad abstracta sobre los actos de la administración de inferior categoría y, por ello, puede ser ejercida en todo tiempo por cualquier persona. Lo que significa que no tiene caducidad mientras el acto cuestionado aún esté surtiendo efectos jurídicos. El accionante no podrá desistir de la acción, pues el interés no es particular sino general63.

Si la Jurisdicción Contencioso Administrativa es competente para conocer de la nulidad de los actos administrativos emanados de las autoridades del orden nacional, departamental, municipal y demás entes administrativos, dicha competencia no puede interpretarse como una rueda suelta y discrecional, sino que está sometida a un último referente de validez, que es la Constitución o, tal como se dijo antes, el Bloque de Constitucionalidad. En este sentido ha dicho la Corte:

"Conservando la misma línea de pensamiento, ha precisado la Corte que la autonomia e independencia judicial, como manifestación de la facultad que tiene el operador jurídico para interpretar las normas jurídicas, no es absoluta. Ella encuentra limites claros en la propia institucionalidad y en el orden jurídico. Así, la función judicial, analizada desde la perspectiva del conjunto de atribuciones y potestades reconocidas por la ley a los órganos encargados de administrar justicia, tiene necesariamente que desarrollarse dentro del marco de la Constitución Política, como la única forma de garantizarles a los coasociados la convivencia, el trabajo, la igualdad, la libertad, la justicia y la paz, y de procurar hacer efectivo el propósito Superior de asegurar un orden politico, económico y social justo" 64 .

\footnotetext{
62 Artículo 137 de la Ley No 1437. Código de Procedimiento Administrativo y de lo Contencioso Administrativo.

63 Santofimio (2004), pp. 137 y ss.

64 Corte Constitucional de Colombia, Sentencia SU 1185 de 2001. M.P. Rodrigo Escobar Gil.
} 


\subsection{Control de constitucionalidad realizado por los jueces}

La acción de tutela consagrada en el artículo 86 de la Constitución Política de 1991, y reglamentada por el Decreto No 2591 del mismo año, es el mecanismo de protección de los derechos fundamentales y su titular es toda persona. Quien creyere que una autoridad pública y, en algunos casos, particulares, ya sea por acción u omisión, ha vulnerado uno o varios derechos de este rango, puede acudir ante un juez de la República -es de anotar que en Colombia no existen los jueces especializados en tutelas, sino que conocer de ellas es una competencia del poder judicial en general, incluyendo los jueces de la Jurisdicción Contencioso Administrativa-. Se trata de un control de constitucionalidad concreto y procede cuando no existe otro mecanismo de protección o, existiendo, se pretenda la intervención inmediata del juez con el fin de evitar que se produzca un daño grave e irremediable ${ }^{65}$.

La protección judicial, que en ningún caso podrá tardar más de diez días, consistirá en una orden dirigida al accionado, para que se abstenga de seguir vulnerando el o los derechos en cuestión so pena de ser sancionado con arresto y multas. Cualquiera de las partes podrá impugnar la orden y en tal caso será el superior jerárquico del juez quien confirmará, modificará o negará la orden de protección del derecho.

Colombia tardó 22 años en cumplir un compromiso adquirido internacionalmente desde 1969, al obligarse con la creación de un mecanismo rápido y efectivo para la protección de los derechos fundamentales que estaba establecido en el artículo 25 numeral $1^{\circ}$ de la Convención Americana de Derechos Humanos, y que dice:

"1. Toda persona tiene derecho a un recurso sencillo y rápido o a cualquier otro recurso efectivo ante los jueces o tribunales competentes, que la ampare contra actos que violen sus derechos fundamentales reconocidos por la Constitución, la ley o la presente Convención, aun cuando tal violación sea cometida por personas que actuen en ejercicio de sus funciones oficiales".

La institución de la tutela ha mostrado sus bondades al permitirles a los colombianos, a través de un procedimiento informal y de poca duración, hacer valer sus derechos humanos fundamentales. En un país donde los procesos judiciales pueden tardar décadas, muchos consideran que las garantías jurídicas

65 Corte Constitucional de Colombia, Sentencia T 117 de 1995. M.P. José Gregorio Hernández Galindo. 
ordinarias no son efectivas y ven en la tutela el instrumento de materialización de esta categoría de derechos -téngase en cuenta que los derechos fundamentales en Colombia no son taxativos, lo que ha creado un objeto de protección indeterminado-. Al preguntarle a la expresidenta de la Corte Constitucional, Magistrada María Victoria Calle, “¿cuántas tutelas se han presentado en el país en estos 25 años y cuántas han sido seleccionadas por la Corte Constitucional?" respondió:

"A la Corte Constitucional ha llegado en estos 25 años un número aproximado de 5 millones y medio de procesos de tutela, de los cuales ha resuelto 17606. La tutela ha sido un valioso instrumento para la protección de los derechos fundamentales de las personas, del cual infortunadamente algunas personas abusan. Por cierto, que es dificil encontrar un buen invento humano que no envuelva el riesgo de abuso, o que no sea usado contra los fines bondadosos que persiguió en sus origenes. Desde luego que la tutela puede necesitar ajustes, pues sus problemas no han de deberse únicamente a las personas sino también a la institución. Pero en general es una institución magnifica, que solo requeriría ajustes moderados" 66 .

Aunque son más los defensores de la acción de tutela, esta también ha tenido sus críticos:

"El argumento central es que existe un abismo, y no pocas contradicciones, entre la jurisprudencia constitucional y la acción de tutela. La primera es flexible, dinámica y ha mostrado ser adaptable a la realidad mientras la segunda, supuestamente informal, es rígida y está sofocada por los plazos breves e inmodificables. La inflexibilidad de los términos -un espejismo de agilidad heredado del formalismo-corroe su funcionamiento, impide su calidad, condena sus posibilidades de adaptación y está causando perjuicios en la justicia ordinaria. La jurisprudencia constitucional tiene altísimo nivel, es elegante, elaborada, profunda, decantada pero dinámica, sofisticada, respetada. La acción de tutela, a pesar de su popularidad, es burda, desorganizada, poco predecible, a veces desconcertante y está teniendo efectos indeseables sobre el entorno jurídico. En buena parte porque sigue hundida en la informalidad; es una especie de San Victorino de la justicia. Lo más dramático es que asi se la promovió, como un instrumento informal. La jurisprudencia constitucional ha demostrado ser, como pregona el nuevo derecho, un sustituto idóneo del legislativo. La acción de tutela, por el contrario, está mostrando las mismas limitaciones formalistas de la justicia tradicional para adaptarse a la realidad, para defenderse de los tinterillos y para hacer cumplir las normas. A pesar de lo anterior-una jurisprudencia consolidada con una justicia de primera instancia que causa

66 Calle (2016). 
creciente daño colateral- se sigue argumentando, con frágil evidencia, que la segunda es indispensable para la primera"67.

Como se dijo antes, en Colombia no existen jueces especializados en tutelas, sino que todos - con algunas excepciones- son competentes para conocer de ellas. Existe un control difuso de constitucionalidad, aunque todas las presentadas en el país van a la Corte Constitucional, pero, como se dijo antes, en su gran mayoría no son seleccionadas y no son objeto de revisión. Además, los jueces pueden apartarse del precedente en aquellos casos en los que justifiquen la razón de su distanciamiento, lo que es un gran poder y frente a grandes poderes deben existir, necesariamente, grandes límites ${ }^{68}$. Dentro del trámite de la tutela la autoridad judicial es protagonista, pues, al tratarse de un trámite sumario, está sometida a pocas normas y ostenta un amplio margen de interpretación.

Uno de los aspectos más problemáticos en esta materia es el de la tutela contra providencias judiciales. En Colombia se han revocado decisiones de tribunales de cierre -Corte Suprema de Justicia y Consejo de Estado- a través de decisiones de jueces de menor jerarquía o de la Corte Constitucional, lo que ha puesto en riesgo la estabilidad del sistema judicial.

Para intentar superar esta situación, en el año 2000 el Gobierno Nacional expidió el Decreto No 1382 que estableció reglas de reparto para la materia. Esta norma ha sido muy cuestionada por regular aspectos de la tutela mediante un decreto ordinario, a pesar de que la Constitución de Colombia dice en el artículo 152 que la regulación de los derechos fundamentales y sus mecanismos de protección debe hacerse por ley estatutaria. También ha generado polémica por romper la estructura tripartita del proceso al fijar que, en aquellos casos donde se instauren tutelas contra el Consejo de Estado o la Corte Suprema de Justicia, de ellas conocerá la misma Corporación, lo anterior en los siguientes términos consignados en el artículo 1, numeral 2 del Decreto:

"Lo accionado contra la Corte Suprema de Justicia, el Consejo de Estado o el Consejo Superior de la Judicatura, Sala Jurisdiccional Disciplinaria, será repartido a la misma

67 Rubio (2011).

68 En Colombia mucho se ha debatido acerca de cuál es la fuerza vinculante de la jurisprudencia, pues la Constitución (artículo 230) llama esta fuente formal del derecho como "criterio auxiliar de la actividad judicial”, pero en estos 27 años de vigencia de la Constitución de 1991, la jurisprudencia ha ido ganado protagonismo hasta el punto de tener fuerza vinculante relativa y no es absoluta, porque los jueces pueden apartarse del precedente judicial en aquellos casos que justifiquen clara y razonadamente los motivos de su distanciamiento. Ver Sentencias C 836 de 2001, C 634 de 2011, C 621 de 2015, entre otras. 
corporación y se resolverá por la Sala de Decisión, sección o subsección que corresponda de conformidad con el reglamento al que se refiere el artículo 4 o del presente decreto".

Son muchas las tutelas que se instauran en el país y por múltiples razones. Existe la creencia generalizada de que la tutela sirve para hacer valer cualquier derecho subjetivo -se han presentado incluso tutelatones ${ }^{69}$. Como los derechos fundamentales no están positivizados, ha quedado a interpretación de los jueces satisfacer sus demandas, incurriendo en muchos casos en órdenes absurdas. Está claro que el control de constitucionalidad en materia de tutela también tiene sus falencias, aunque no se puede desconocer la importancia de esta figura dentro del constitucionalismo colombiano.

\subsection{Control de constitucionalidad realizado por los servidores públicos y particulares con el deber de aplicar una norma jurídica}

El modelo norteamericano inspiró en 1910 la creación de la excepción de inconstitucionalidad en Colombia, la cual sigue aún vigente y les permite a los servidores públicos -incluyendo los jueces- y a los particulares, que tengan el deber de aplicar una norma, que la inapliquen porque prefieren la Constitución. Los efectos de la inaplicación de la norma son inter partes y no erga omnes, sin embargo, por la influencia jurídica del modelo europeo continental, dicha institución no ha tenido en Colombia mayor eficacia:

"La idea de la supremacía constitucional, que sin lugar a dudas fue tomada de la experiencia jurídica norteamericana, no se consolidó en su totalidad, a pesar de los distintos intentos para su consagración se hiciera desde los mismos albores de nuestra independencia. Por otra parte, en Colombia, como en todos aquellos ordenamientos que se vertebran en torno a la visión civilista impuesta por la fuerza sugestiva de la Revolución francesa y el código de Napoleón, arquitectura expresiva de la más depurada racionalización jurídica, el poder judicial nace estigmatizado y se concibe como un súbdito incondicional de la ley o de la voluntad del legislador.

69 En Colombia se ha dado el nombre de tutelatones a convocatorias masivas de líderes políticos para que sus seguidores de manera individual instauren tutelas en favor de satisfacer intereses comunes, sucedió en 2013 cuando el entonces alcalde de Bogotá Gustavo Petro fue destituido por la procuraduría y éste llamó a sus votantes para que vía tutela hicieran valer su derecho político a elegir, y más recientemente en septiembre de 2016 con el llamado por el Representante a la Cámara Santiago Valencia del partido Centro Democrático -opositor al Gobierno Nacional-, para que se suspendiera el plebiscito del 2 de octubre de 2016. Para regular estos casos el Gobierno Nacional expidió el Decreto No 1834 de 2015. 
Esta cultura legalista, escenario cotidiano de nuestras reflexiones y practicas jurídicas, no permitió la asimilación apropiada de la excepción como forma de control constitucional, pues el poder judicial carecía de la autonomía necesaria que activara o dinamizara esa modalidad prescindiendo del consentimiento de la ley y realizando una lectura que condujera a la aplicación directa de la Constitución. Fue en esa coyuntura que prevaleció finalmente la forma de control constitucional que acudia a la acción como medio más idóneo para lograr una decisión que solucionara los conflictos normativos de carácter vertical suscitados entre la ley u otras normas jerárquicamente inferiores y la Constitución. Solución esta que exhibe, en sus decisiones, las citadas caracteristicas: son formales, generales y definitivas" 70 .

El sustento normativo de esta figura se encuentra en los artículos $4^{\circ}$ de la Constitución Política, 20 de la Ley No 393 de 1997, 148 de la Ley No 1437 de 2011, entre otros. La excepción de inconstitucionalidad no es una declaratoria de inconstitucionalidad ${ }^{71}$. No trae consigo consecuencias en abstracto. Se trata de control de constitucionalidad concreto y sus efectos son inter partes ${ }^{72}$, pues la norma inaplicada sigue vigente para los demás casos. Sin embargo, es posible hablar de efectos inter pares, es decir, que quienes estén en una situación similar tienen derecho a ser tratados de manera analógica, cuando la autoridad que ordena la inaplicación de la norma es la Corte Constitucional, y concurran cinco condiciones fácticas a saber:

“a) Que la excepción de inconstitucionalidad resulte de la simple comparación de la norma inferior con la Constitución, de la cual surja una violación, no solo palmaria, sino inmediata y directa de una norma constitucional especifica.

b) Que la norma constitucional violada, según la interpretación sentada por la Corte Constitucional, defina de manera clara la regla jurídica que debe ser aplicada.

c) Que la inconstitucionalidad pueda ser apreciada claramente, sin que sea necesario sopesar los hechos particulares del caso y, por lo tanto, la inconstitucionalidad no dependa de tales hechos.

\footnotetext{
70 Herrera Gómez (2002), pp. 95 y 96.

71 Algunas providencias expedidas por la Corte Constitucional colombiana sobre la excepción de inconstitucionalidad son: T 513 de 1997. M.P. Arango Mejía; T 556 de 1998. M.P. José Gregorio Hernández Galindo; C 600 de 1998. M.P. José Gregorio Hernández Galindo; C 037 de 2000. M.P. Vladimiro Naranjo Mesa; T 1290 de 2000. M.P. José Gregorio Hernández Galindo; Auto 071 de 2001. Sala plena; T 1033 de 2008. M.P. Rodrigo Escobar Gil; T 977 de 2012. M.P. Alexei Julio Estrada; T 681 de 2016. M.P. Jorge Iván Palacio.

72 Corte Constitucional de Colombia, Sentencia C 600 de 1998. M.P. José Gregorio Hernández Galindo.
} 
d) Que la norma inaplicada regule materias sobre las cuales la Corte Constitucional ha sido investida por la Constitución de una responsabilidad especial, como es el caso de la acción de tutela y la protección efectiva de los derechos fundamentales, en virtud del artículo 241 numeral 9 y del inciso $2^{\circ}$ del artículo 86 de la Carta.

e) Que la decisión haya sido adoptada por la Sala Plena de la Corte en cumplimiento de su función de unificar la jurisprudencia o haya sido reiterada por ella"73.

Cuando se den los anteriores requisitos, entonces todo aquel que esté en una situación similar al caso fallado por la Corte, tendrá derecho a ser tratado de manera analógica.

La inaplicación de una norma, por considerarla inconstitucional, es de carácter excepcional, pues contradice la presunción de constitucionalidad de las normas jurídicas. Puede solicitarla cualquiera que tenga un interés legítimo para su inaplicación en un caso concreto, y no aquel que solo pretenda por interés general la preservación de la supremacía constitucional, para estos casos está la acción de inconstitucionalidad 74 .

Aunque la acción de tutela no procede contra actos generales, impersonales y abstractos $^{75}$, sí puede utilizarse este mecanismo de protección de derechos humanos fundamentales en aquellos casos en los que se pretenda la inaplicación por parte de una autoridad de una norma que, en un caso concreto, contradice la Constitución ${ }^{76}$. Según la Corte Constitucional, las autoridades que están facultadas para inaplicar una norma jurídica infraconstitucional son:

"De otra parte hay que tener en cuenta que el control por vía de excepción lo puede realizar cualquier juez, autoridad administrativa e incluso particulares que tengan que aplicar una norma jurídica en un caso concreto".

Lo anterior entrega un poder muy grande en cabeza de muchas personas que, no necesariamente, tienen la formación y la técnica jurídica para ejercerlo.

\footnotetext{
73 En el numeral 4 del Auto 071 de 2001, la Corte Constitucional de Colombia, siendo el Magistrado Sustanciador Manuel José Cepeda Espinosa, ordenó: "Cuarto. Otorgar efectos inter pares a la decisión de inaplicar el artículo $1^{\circ}$ del Decreto $N^{\circ} 1382$ de 2000, para que en aquellos casos que sean semejantes todos los jueces de tutela apliquen la excepción de inconstitucionalidad en el mismo sentido".

74 Corte Constitucional de Colombia, Sentencia T 389 de 2009. M.P. Humberto Sierra Porto.

75 Artículo 6, numeral 5) Decreto No 2591 de 1991.

76 Corte Constitucional de Colombia, Sentencia T 389 de 2009. M.P. Humberto Sierra Porto.
} 
Confirmando lo inseguro y confuso que es el modelo de control de constitucionalidad en Colombia.

Existe indeterminación a la hora de que cualquiera de las anteriores autoridades pretenda hacer uso de la excepción de inconstitucionalidad, pues no existe un procedimiento reglado que establezca etapas, recursos y demás garantías procesales. Es la Corte Constitucional la que, por vía jurisprudencial, ha establecido algunos lineamientos, que en la práctica resultan insuficientes:

"Ahora bien, con relación a las condiciones que se exigen para la aplicación de la excepción de constitucionalidad, aspecto sobre el cual el actor hace énfasis, la Corte ha señalado que la contradicción entre las normas constitucional y legal debe ser clara y evidente, $y$ debe estar precedida de argumentos suficientes en los cuales se soporte la decisión. Una decisión de esta naturaleza debe tener en cuenta la jurisprudencia proferida por el intérprete autorizado de la Carta. Ello, en particular, dada la especial estructura de las normas constitucionales y las dificultades especiales de interpretación que dicha estructura ofrece. De no respetarse las reglas anteriores, las personas quedarian libradas a la voluntad y libre valoración de cada operador jurídico, en contravía de la presunción de constitucionalidad que acompaña a las disposiciones legales y de los principios de igualdad y confianza en la administración de justicia (seguridad juridica) cuya protección exige la Constitución.

En esta medida, la Corte ha concluido que, si no hay un precedente constitucional en la materia o una oposición evidente con los mandatos de la Carta, habrá de estarse a lo que disponen las disposiciones de inferior jerarquia (presunción de constitucionalidad), pues "la norma jurídica, independientemente de su jerarquía, obliga a sus destinatarios $y$ es deber de las autoridades públicas, en el ámbito de las atribuciones que a cada una de ellas corresponda, hacerla efectiva"77.

La excepción de inaplicación constitucional no puede ser una rueda suelta dentro del sistema normativo y la oportunidad de unos pocos de evadir el peso de la ley, pues sería la generalización del caos y la pérdida de la seguridad jurídica. Así lo han manifestado algunos doctrinantes colombianos:

"La estabilidad del sistema que nos rige parte de la presunción de que toda ley se ajusta a las normas constitucionales mientras no haya sido declarada inexequible por la Corte Suprema de Justicia (función que cumple hoy la Corte Constitucional), lo que hace que la disposición de artículo 215 de la Carta (artículo 4 de la Constitución de 1991) sea

77 Corte Constitucional de Colombia, Sentencia T 808 de 2007. M.P. (E). Catalina Botero Marino. 
de naturaleza excepcional y de aplicación restringida, ya que su abuso conduciría al desquiciamiento del orden jurídico"78.

En Colombia es evidente la imprecisión conceptual de esta forma de control, que conduce lógicamente a su inutilización práctica ${ }^{79}$. El desuso de la excepción de inaplicación constitucional en el país obedece a la falta de estructura jurídica de la figura, pues carece de un procedimiento reglado y unas instancias coherentes para su uso ${ }^{80}$. Así mismo, existe incertidumbre a la hora de utilizarla, debido al grado de indeterminación del artículo $4^{\circ}$ de la Constitución Política de Colombia y demás normas concordantes, en las cuales no se determina una autoridad que tenga la última palabra frente a la norma inaplicada, lo que ocasiona inseguridad jurídica ${ }^{81}$.

78 Extracto citado por Charry UREŃa (1994), pp. 80 a 82.

79 "Bien valdría la pena entonces la realización hoy de un trabajo de campo que permitiera detectar y cuantificar los índices de utilización o recurrencia a esta forma de control por parte de los jueces ordinarios en la actualidad, pues que se evidencia todavía la insuficiente comprensión y precisión conceptual respeto de esta figura, lo que conduce a su no utilización.

Hoy, esos jueces continúan ignorando el deber jurídico que implica para ellos ese control difuso consagrado en el artículo 4 de la Carta Fundamental. En el mejor de los casos, se ciñen a sentencias de las altas cortes, en particular de la Corte Constitucional, calcando los argumentos y razonamientos efectuados por ella en casos idénticos a los que van a decidir. No realizan ellos mismos un análisis de la constitucionalidad de las normas aplicables en principio al caso que van a resolver, no se apropian del método utilizado por la Corte al enjuiciar esa constitucionalidad, sino que siguen mecánicamente los razonamientos ya elaborados por ella en casos o situaciones idénticas". Herrera Gómez et al. (2002), p. 111.

80 "Esta circunstancia a mi juicio, es aquello que debería instaurarse en nuestro régimen jurídico para conjurar las críticas en torno a la certeza del derecho y la seguridad jurídica que se exponen sobre el tema del control de constitucionalidad por vía de excepción y de esta manera se regularía mejor esta especie de control difuso y habría mayor certidumbre, así como seguridad para poder aplicarse, como sucede en el derecho comparado en el caso del control incidental donde hay un organismo especializado que en nuestro caso bien podría ser la Corte Constitucional para conocer de las cuestiones de inconstitucionalidad que se propongan en un determinado litigio y resolverlas. Esta solución se propuso en el proyecto de Reforma Constitucional presentado a las Cámaras Legislativas por el expresidente César Gaviria Trujillo, pero desafortunadamente no prosperó”. Bernal CANO (2002), p. 146.

81 La Dra. Natalia Bernal, frente a la necesidad de establecer un mecanismo incidental de consulta ante la Corte Constitucional de las excepciones que se adelanten en el país, en pro de eficacia y seguridad jurídica, dijo: "Es importante considerar, que para que la excepción de inconstitucionalidad tenga mayor eficacia y se materialice como mecanismo real para la defensa de los preceptos constitucionales y su supremacía sobre los legales, es menester adoptar un sistema de control de constitucionalidad que se caracterice por ser articulado, uniforme, serio, objetivo, que se dirija a mantener incólume la supremacía Constitucional y la protección de los derechos y las garantías de las personas, sin que ello implique la inactividad de los operadores jurídicos como lo son los jueces ordinarios la actividad controladora”. BERnAL CANO (2002), p. 294. 
Una propuesta encaminada al orden sería regular el trámite de inaplicación, establecer un procedimiento expedito para que solo los jueces puedan inaplicar normas infraconstitucionales a petición de cualquier otra autoridad pública o particular con el deber de aplicar una norma jurídica. Los efectos de la decisión judicial serían inter partes y de primera instancia, sin la posibilidad de reposición o apelación en pos de la celeridad del trámite. Todas las decisiones judiciales de inaplicación deberían ser enviadas a la Corte Constitucional para que esta actúe como segunda y última instancia y efectúe su control de constitucionalidad. Si la Corte ordena la inaplicación de la norma, entonces instaurará un precedente que impedirá que otras autoridades la utilicen en casos similares. En este sentido, la Corte Constitucional ya ha establecido la necesidad de que sus decisiones por vía de inaplicación tengan efectos erga omnes y no simplemente inter partes:

"Finalmente, no sobra recordar que dentro del sistema Europeo Continental de control de constitucionalidad, precisamente debido a sus elementos concentrados dominantes, la regla general cuando una Corte Constitucional ejerce, no el control abstracto de normas sino el control concreto de constitucionalidad, es que sus providencias también tienen efectos erga omnes. Esa es la regla general adoptada en los países europeos donde existe un control concreto de constitucionalidad independientemente de las características especificas de los diversos mecanismos para desencadenarlo. Hay dos excepciones, la belga y la portuguesa. Sin embargo, en estos dos paises existen procedimientos para asegurar que los efectos del control concreto no sean exclusivamente inter partes" 82 .

\section{CONClusiones}

Durante sus más de 200 años de vida republicana, Colombia ha construido un complejo e inseguro sistema de control de constitucionalidad, muchos son los doctrinantes colombianos que cuestionan nuestro modelo.

Existen múltiples mecanismos para hacer efectiva la Constitución y muchos garantes de esta, como la acción de inconstitucionalidad ante la Corte Constitucional, la acción de nulidad por inconstitucionalidad ante el Consejo de Estado, la nulidad ante la Jurisdicción Contencioso Administrativa, la tutela ante los jueces y la excepción de inconstitucionalidad de la que pueden hacer uso todos

82 Corte Constitucional de Colombia, Auto 071 de 2001. Magistrado Sustanciador: Manuel José Cepeda Espinosa. 
los servidores públicos, incluyendo los jueces e, incluso, los particulares con el deber de aplicar una norma jurídica.

Es complejo pues se ha generado un sistema en el que se presentan conflictos de competencia, como los que se han dado entre la Corte Constitucional y el Consejo de Estado a la hora de determinar la constitucionalidad de algunos decretos. Esto se solucionaría dejando en cabeza de la Corte Constitucional la facultad de revisar todos los decretos emanados del Gobierno Nacional. Otro aspecto problemático ha sido la revisión de tutelas por parte de la Corte Constitucional en las que el accionado es la Corte Suprema de Justicia o el Consejo de Estado.

En el año 2001 se expide la Sentencia C 1052 que, según la Corte Constitucional, buscaba evitar las sentencias inhibitorias, desde entonces este tipo de decisiones no ha disminuido y, al contrario, en la mayoría de los años aumentaron. Las que sí disminuyeron fueron las sentencias C, resultado de peticiones ciudadanas, lo que significa que la Corte desde entonces es más exigente en su proceso de admisión. En Colombia, la acción de inconstitucionalidad es un derecho ciudadano y condicionarlo a una excesiva argumentación vulnera otros derechos, tales como la supremacía efectiva de la Constitución, el acceso a la justicia y la tutela jurisdiccional efectiva.

El Congreso de la República y el Gobierno Nacional han encontrado fórmulas para eludir el control de constitucionalidad, pues asuntos que deberían ser reglados por leyes el Gobierno, los ha regulado por decretos reglamentarios, o algo que podría ser regulado por ley se eleva a rango constitucional a través de un acto legislativo, evitando así el control material.

Existen garantías constitucionales ineficaces y desarticuladas que no cumplen con el propósito para el que fueron creadas, como es el caso de la excepción de inconstitucionalidad y otras de las que se ha abusado y han requerido importantes reformas, como ha sucedido con la tutela.

No se quiere menoscabar la figura de la inaplicación constitucional, al contrario, es necesario vigorizarla, pero dentro de un marco jurídico claro que le dé mayor difusión, aplicabilidad y eficacia. Mientras lo anterior no suceda, el desarrollo conceptual de la inaplicación constitucional seguirá proviniendo de la jurisprudencia. En el caso de la tutela, se debe establecer un sistema de precedentes fuerte que someta a todos los jueces a unas mismas reglas claras, en favor de la seguridad y eficacia de la institución. 
El control de constitucionalidad en Colombia es un sistema compuesto por múltiples normas, mecanismos y procedimientos, es confuso e inseguro porque cuando hay tantas normas que hacer cumplir, tantas autoridades que lo realizan y no todos los procedimientos están reglados ni sujetos a mecanismos de verificación, cada cual puede estar tentado a actuar, no conforme a la Constitución, sino a intereses particulares y en Colombia, para infortunio nuestro, ya ha pasado.

\section{Bibliografía CITADA}

Aguilar, Gonzalo (2017). "El control de convencionalidad y control de constitucionalidad: ¡juntos, pero no revueltos!”, en Nogueira, Humberto y Aguilar, Gonzalo (Coord.) Control de convencionalidad, corpus iuris y ius commune interamericano (Santiago de Chile, Editorial Triángulo), pp. 54-87.

Bernal Cano, Natalia (2002). La excepción de inconstitucionalidady su aplicación en Colombia (Medellín, Ediciones Jurídicas Gustavo Ibáñez).

Botero, Catalina y Jaramillo, Juan Fernando (s.f.). "El conflicto de las altas cortes colombianas en torno a la tutela contra sentencias", [fecha de consulta: 23 de noviembre de 2016]. [Disponible en: http://www.dejusticia.org/files/ r2_actividades_recursos/fi_name_recurso.37.pdf].

BREWER-CARIAS, Allan (1995). Sistema mixto o integral de control de constitucionalidad en Colombia y Venezuela (Bogotá, Universidad del Externado Colombia y Pontificia Universidad Javeriana).

Calle, María Victoria (2016). "Constitución Política: hemos recibido 5,5 millones de tutelas en 25 años”, entrevista concedida el 3 de julio de 2016, en El Colombiano, Medellín, [fecha de consulta: 22 de noviembre de 2016]. [Disponible en: http://m.elcolombiano.com/constitucion-politica-hemosrecibido-5-5-millones-de-tutelas-en-25-anos-MY4504358].

Gaona Cruz, Manuel (1984). Aspectos del control constitucional en Colombia. (Bogotá, Universidad Externado de Colombia).

Herrera Gómez, Ana Lucía y otros. (2002). La inaplicabilidad de la jurisdicción constitucional (Medellín, Editorial Universidad de Antioquia).

Mendieta González, David (2010). "La acción pública de inconstitucionalidad: a propósito de los 100 años de su vigencia en Colombia”, en Vniversitas (No 120), pp. 61-83. 
Mendieta GonzÁlez, David (2016). Manual de introducción al estudio de Derecho (Medellín, Fondo Editorial Remington).

Mendieta González, David (2017). La acción de inconstitucionalidad en Colombia: ¿puede la Corte Constitucional establecer límites al ejercicio ciudadano de esta acción? Memoria para optar al Grado de Doctor por la Universidad Complutense de Madrid (Madrid, Universidad Complutense de Madrid).

Nogueira, Humberto (2017). "El control de convencionalidad por las jurisdicciones nacionales", en Control de convencionalidad, corpus iuris y ius commune interamericano (Santiago de Chile, Editorial Triángulo), pp. 11-53.

Quinche Ramírez, Manuel (2009). La elusión constitucional: una politica de evasión del control de constitucionalidad en Colombia (Bogotá, Universidad del Rosario).

Restrepo Piedrahíta, Carlos (1978). Tres ideas constitucionales (Bogotá, Universidad Externado de Colombia).

Restrepo Yepes, Juan y Restrepo-Yepes, Olga (2017). "Naturaleza jurídica de los decretos de ley marco y su control judicial”, en Opinión Jurídica (No 32), pp. 127-154.

Rubio, Mauricio (2011). “Tutela: entre la informalidad y el formalismo”, [fecha de consulta: 24 de noviembre de 2016]. [Disponible en: http://mrptrabajo. blogspot.com.co/2011_06_01_archive.html].

Rubio Llorente, Francisco (1989). "Bloque de constitucionalidad", en Revista Española de Derecho Constitucional (año 9, número 27), pp. 9-37.

Santofimio G., Jaime Orlando (2004). Tratado de Derecho Administrativo. (Bogotá, Universidad Externado de Colombia).

Tóón Tobón, Mary Luz y Mendieta, David (2017). "Los estados de excepción en el régimen constitucional colombiano", en Opinión Jurídica (No 31), pp. 67-88.

Тово́n Tов́́N, Mary Luz (2016). "La conmoción interior: el juicio de constitucionalidad a la luz de la Constitución Política de Colombia de 1991”, en Prolegómenos, Vol. 19 (No 38), pp. 145-160.

Uprimny, Rodrigo (2003). "El bloque de Constitucionalidad en Colombia. Un análisis jurisprudencial y un ensayo de sistematización doctrinal”, en Compilación de jurisprudencia y doctrina nacional e internacional. Derechos Humanos, Derecho Internacional Humanitario y Derecho Penal Internacional. $3^{a}$ ed., Vol. I. (Bogotá, Oficina en Colombia del Alto Comisionado de las Naciones Unidas para los Derechos Humanos). 


\section{NORMAS JURÍDICAS CITADAS}

Constitución Política de Colombia de 1991.

Convención Americana de Derechos Humanos.

Decreto No 2067 de 1991 por el cual se dicta el régimen procedimental de los juicios y actuaciones que deban surtirse ante la Corte Constitucional. Diario Oficial No 40012 de septiembre 4 de 1991.

Decreto No 2591 por el cual se reglamenta la acción de tutela consagrada en el artículo 86 de la Constitución Política. Diario Oficial No 40165 de noviembre 19 de 1991.

Ley No 270 estatutaria de la administración de justicia, Diario Oficial No 42745 de marzo 15 de 1996.

Decreto No 1382 por el cual se establecen reglas para el reparto de la acción de tutela. Diario Oficial No 44082 de julio 14 de 2000.

Acto Legislativo 03 por el cual se reforma la Constitución Nacional, Diario Oficial No 45040 de diciembre 19 de 2002.

Ley No 1437 por la cual se expide el Código de Procedimiento Administrativo y de lo Contencioso Administrativo, Diario Oficial No 47956 de enero 18 de 2011.

Acuerdo 02 de 2015 por medio del cual se unifica y actualiza el reglamento de la Corte Constitucional de Colombia, 22 de julio de 2015.

Acto Legislativo 01 de 2016 por medio del cual se establecen instrumentos jurídicos para facilitar y asegurar la implementación y el desarrollo normativo del acuerdo final para la terminación del conflicto y la construcción de una paz estable y duradera. Diario Oficial No 49.927 de julio 7 de 2016.

Acto Legislativo 01 de 2017 por medio del cual se crea un título de disposiciones transitorias de la Constitución para la terminación del conflicto armado y la construcción de una paz estable y duradera, y se dictan otras disposiciones. Diario Oficial No 50196 de abril 4 de 2017.

Acto Legislativo 02 por medio del cual se adiciona un artículo transitorio a la Constitución con el propósito de dar estabilidad y seguridad jurídica al acuerdo final para la terminación del conflicto y la construcción de una Paz Estable y Duradera, Diario Oficial No 50230 de mayo 11 de 2017.

Decreto No 121 de 2017 por el cual se adiciona un capítulo transitorio al Decreto No 2067 de 1991. Diario Oficial No 50128 de enero 26 de 2017. 


\section{JURISPRUDENCIA COLOMBIANA CITADA}

Corte Constitucional de Colombia, Sentencia C 674 de 2017, M.P. Luis Guillermo Guerrero Pérez.

Corte Constitucional de Colombia, Sentencia C 630 de 2017, M.P. Luis Guillermo Guerrero Pérez y Antonio José Lizarazo Ocampo.

Corte Constitucional de Colombia, Sentencia T 174 de 2017. M.P. María Victoria Calle Correa.

Corte Constitucional de Colombia, Sentencia C 699 de 2016. M.P. María Victoria Calle Correa.

Corte Constitucional de Colombia, Sentencia T 272 de 2014. M.P. María Victoria Calle.

Corte Constitucional de Colombia, Sentencia C 400 de 2013. M.P. Nilson Pinilla.

Corte Constitucional de Colombia, Sentencia C 049 de 2012. M.P. Mauricio González Cuervo.

Corte Constitucional de Colombia, Sentencia C 415 de 2012. M.P. Mauricio González Cuervo.

Corte Constitucional de Colombia, Sentencia C 122 de 2011. M.P. Juan Carlos Henao Pérez.

Corte Constitucional de Colombia, Sentencia C 539 de 2011. M.P. Luis Ernesto Vargas Silva.

Corte Constitucional de Colombia, Sentencia T 389 de 2009. M.P. Humberto Sierra Porto.

Corte Constitucional de Colombia, Sentencia T 808 de 2007. M.P. (E). Catalina Botero Marino.

Corte Constitucional de Colombia, Sentencia C 028 de 2006. M.P. Humberto Sierra Porto.

Corte Constitucional de Colombia, Sentencia C 1300 de 2005. M.P. Marco Gerardo Monroy Cabra.

Corte Constitucional de Colombia, Sentencia C 426 de 2002. M.P. Rodrigo Escobar Gil.

Corte Constitucional de Colombia, Sentencia T 203 de 2002. M.P. Manuel José Cepeda.

Corte Constitucional de Colombia, Sentencia SU 1185 de 2001. M.P. Rodrigo Escobar Gil. 
Corte Constitucional de Colombia, Sentencia SU 1023 de 2001. M.P. Manuel José Cepeda.

Corte Constitucional de Colombia, Auto 071 de 2001. Magistrado Sustanciador: Manuel José Cepeda Espinosa.

Corte Constitucional de Colombia, Sentencia C 534 de 2000. M.P. Eduardo Cifuentes Muñoz.

Corte Constitucional de Colombia, Sentencia C 600 de 1998. M.P. José Gregorio Hernández Galindo.

Corte Constitucional de Colombia, Sentencia C 191 de 1998. M.P. Eduardo Cifuentes Muñoz.

Corte Constitucional de Colombia, Sentencia C 037 de 1996. M.P. Vladimiro Naranjo Mesa.

Corte Constitucional de Colombia, Sentencia C 666 de 1996. M.P. José Gregorio Hernández Galindo.

Corte Constitucional de Colombia, Sentencia C 225 de 1995. M.P. Alejandro Martínez Caballero.

Corte Constitucional de Colombia, Sentencia C 578 de 1995. M.P. Eduardo Cifuentes Muñoz.

Corte Constitucional de Colombia, Sentencia T 117 de 1995. M.P. José Gregorio Hernández Galindo.

Corte Constitucional de Colombia, Sentencia C 513 de 1994. M.P. Antonio Barrera Carbonell.

\section{JURISPRUDENCIA INTERAMERICANA CITADA}

Corte Interamericana de Justicia, Sentencia Almonacid Arellano vs. Chile. Septiembre 26 de 2006, párrafo 124. 